\title{
In Search of the Inspired Student-Measuring of Youth Inspiration in High School-A Youth Economy Paper
}

\author{
Mohamed Buheji \\ Founder of International Institute of Inspiration Economy, Berrechid, Morocco \\ Email: buhejim@gmail.com
}

How to cite this paper: Buheji, M. (2017) In Search of the Inspired Student-Measuring of Youth Inspiration in High School-A Youth Economy Paper. American Journal of Industrial and Business Management, 7, 785-797.

https://doi.org/10.4236/ajibm.2017.76056

Received: May 9, 2017

Accepted: June 19, 2017

Published: June 22, 2017

Copyright $\odot 2017$ by author and Scientific Research Publishing Inc. This work is licensed under the Creative Commons Attribution International License (CC BY 4.0).

http://creativecommons.org/licenses/by/4.0/

\begin{abstract}
Inspiration has been rarely studied in education and pedagogical literature. In fact it is even very hard to find good reference papers about measuring students' inspiration. Student inspiration has nearly been totally away from schools expected outcome. Inspiration is not yet a measure for the return of investment on education. Along the educational journey, in many schools that are considered to be competitive; students have never been challenged to explore their sources of inspiration. In this study we investigate the data for more than 17,000 high school students, after setting the basic criteria's for students' inspiration. The paper addresses what are the situations, the conditions and practices that help in creating waves of inspiration to cover more students. The study concludes with a proposed learning framework and a recommendation for future researches to come. The limitation of the paper mainly is that it was conducted only in one country.
\end{abstract}

\section{Keywords}

Inspiration, Inspiration Economy, Education, Reflective Learning, Youth Economy

\section{Introduction}

There are numerous possible causes of inspiration and especially in youth and undergraduate students. One of the main causes that are repeatedly discussed and indirectly seen in literature could be the lack of students' engagement with real life situations [1].

Psychological experiences play also an important role in creating a generational effect where students are turned to be youth with life-purpose-full, even before attending university or joining the labour market. Jere Brophy [2] cites 
some key points reported by McIntyre on encouraging students and then inspiring their motivation. Brophy [2] mentioned also the importance of gaming as a tool to inspire students towards problem-solving and curiosity. This curiosity can be raised by voting or class discussion which leads to more interaction and element of discovery.

Inspiration as we mentioned in previous work can empower the student to be an active learner and to engage with different topics, communicate with his/her classmates [3].

Stubb [4] explored doctoral students' experiences in terms of scholarly communities and socio-psychological well-being. The Stubb team study examined how experiences related to students' engagement led to enhancement of self-reported stress, exhaustion, and anxiety. Stubb [4] showed that scholarly community as source of burden (56\%), but experiences of inspiration and empowerment were also frequently reported in the answers (44\%). Feelings of empowerment were positively related to study engagement and negatively related to stress, exhaustion, and anxiety. This was seen earlier by Meece [1] team too.

Inspired and empowered students were found to be more likely to engage themselves in the educational process and complete their work in a timely manner. This situation was found to support the students own learning and growth. Stubb [4] and Meece [1] shown that the experiences and self-reported negative emotions indicated that students who experienced their own scholarly community as empowering and inspiring, also experienced less stress, exhaustion, and anxiety in their studies.

In relevance to the above, Souitaris [5] followed by Plucker [6] shown that the entrepreneurial spirit based programs could raise the attitudes and the overall students entrepreneurial intention and inspiration. The findings contribute to the theories of planned behaviour and education. Plucker seen also that student aspirations are related to several educational outcomes, including academic performance, affective health, attrition, and leadership skills. Inspired students found to be ready for mentoring, filled with self-confidence and excitement [6].

The research background of this paper came from a project that was carried out by the researcher to shift the assumptions and paradigm of the criteria's measured today in schools that focus on students competitiveness in the Kingdom of Bahrain and their fitness for the labour market. The context of paper focuses only grade 12 students, i.e. last year high school students. The importance of this paper is that it illustrates what criteria's need to be built in the future for measuring students' competitiveness for instable socio-economy and shows the importance of doing more studies in relevance youth economy and its best development methodologies.

\section{Literature Review}

\subsection{Creating Waves of Inspiration through Blending Achievement Goals in Students Learning}

The study of Zakrajsek [7] setting challenging goals and student achievement. 
Both laboratory and field studies consistently demonstrated decades ago that setting specific and challenging goals leads to enhanced performance. In addition to the immediate increased student achievement resulting from setting goals, completing challenging goals is also closely related to increased self-esteem and self-efficacy.

Janzow and Eison [8] mentioned about the importance of achievement goal orientation as a technique that comes from educational psychology [9]. If humans, including students, manage to set high goals it would have a tremendous impact on how they pursue their goal [3].

The literature is still in thrust for studies that would show how students' competency might be linked or can't be linked to their level of inspiration. We don't have enough evidence how such students are likely to persist if they make an error, or have to put forth a lot of effort because either of these two outcomes would label them as incompetent. However, a recent study of Svinicki [10] shows that more competent students found to prefer to perform tasks that they know they can do, but they're not willing to take any risks for task that are not structured in order not to fail.

In order to create waves of inspiration, teachers should create interest in their students to be more willing to try new things, ask questions in class, and seek out new ideas. Teachers as per Feldman [11] should encourage their students to teach, because as if they are teaching themselves. The Franklin study [12] shows that inspiring students are fun to teach because they share enthusiasm for the content and appreciate the inter-disciplinary relations between the concepts under study.

Locke [13] found that students once engaged in discussions of a complex topic, might glimpse some mastery goals to keep up with the flow of ideas. Students with goal orientations are found here to be related to personality where learners either mastery oriented or performance oriented [13].

Middleton and Midgley [14] confirmed that there are this can be divided into performance approach orientation and performance avoidance orientation. Individuals with a performance approach orientation want to be the best, to appear to be the most competent. As a result, they will work hard and put in a lot of effort in order to surpass their peers. Individuals with a performance avoidance orientation are trying to avoid making mistakes and appearing incompetent. They are the ones more likely to hold back and not take risks in order to lessen their chances of failing. They take the known path, the unchallenging tasks, and they frequently are reluctant to show their work to others until it's perfect [15]. If students develop goals it can influence what they chooses to study. Through goals their persistent would grow and their abilities to face difficulties would develop [13].

\subsection{School Pedagogical Team Role in Creating Inspiration}

Although there is evidence that setting students challenging goals has a number

of positive outcomes, we need to have a pedagogical team in each school whom 
are ready to create and manage these challenges.

Developing challenging learning environments for students by inspired teacher create learning environments whereby students set goals that challenge themselves. Inspiring students set and achieve challenging goals. Johnson and Johnson [15] confirmed that students with encountered with a learning environment that answer their many life related questions are more stimulated to contribute more. The Johnsons study shows that inspiration that lead to achieving goals must come from the students.

Syinicki [10] discussed factors that influence student learning and motivation that teachers need to be aware about. While Janzow and Eison [8] wrote about the new directions in teaching and learning that leads to such motivation. Janzow and Eison warned that teachers need to be careful about the student high orientation toward grades is very high. Janzow and Eison asserted that students displayed two basic orientations toward their studies: a grade orientation (working for the grade) or a learning orientation (working to learn).

Janzow and Eison [8] even described how instructors identify their students tendencies. Students are usually interested in learning something from their classes, but the students also believe that the real currency of the marketplace is still the grades.

If the instructor reacts to a student error with interest and support rather than criticism and withdrawal, students are more likely to view their mistakes in a constructive light. They wouldn't try to hide their mistakes and miss the opportunity to learn from them. Even the model that the instructor presents to the class when mistakes are made influence the student. Rather than becoming defensive or trying to bluff through an error, if the instructor acknowledges the mistake and models how someone should approach correcting that mistake, the students have learned a very good lesson about how they should cope with their own mistakes.

\subsection{Building Self-Determination and Students Inspiration through Learning from Failures}

Students found to be motivated when they are engaged in behaviours they value because they are intrinsically interesting [13].

Self-determination theory asserts that individuals are more motivated to work at a task if there was an element of choice or control involved [8] [16]. Individuals who have choices associated with their efforts are more likely to adopt a mastery orientation. Self-determination need not to be in a risk-free environment since learning is a risky business [15].

Helping students become reflective about their learning so that they base their self-worth on how far they've come rather than on how they compare with others is an important component of getting them to adopt a mastery orientation [14].

Encourage the development of a learning community in the class where everyone is expected to make progress and encouraged to help everyone else make 
progress. The bottom line on encouraging students to adopt a mastery orientation involves giving worthwhile assignments where the focus is on learning and making progress rather than being perfect.

Research on collaborative vs. competitive reward structures seems to indicate that minimizing competition and rewarding collaboration results in better learning, for a whole variety of reasons [17]. Recent efforts towards shifting grading methods away from norm referenced comparative forms of grading to criterion referenced individual achievement grading will also help move the students' focus away from how they compare with others to how much progress they have made and how much further they need to go.

Even the shift to portfolio type grading as opposed to tests as the basis for grades plays a role in shifting student attention toward mastery. In the case of performance avoidance oriented students, their goal is to play it safe and only do what they know will be successful [18].

In reality there is nothing wrong with failure; the problem lies in our reaction to and interpretation of failure. For many individuals, failure is an indication of lack of ability [1]. For others failure simply means that they don't know how to do that specific thing at this specific time. In fact a much healthier interpretation of failure is that it is an opportunity for learning.

In order to build students inspiration teachers should focus on wrong answers not as failures, but more accurately as misunderstandings. No student sets out to give a wrong answer; as far as they're concerned, they're giving a correct answer. Instructors should can use errors as teachable opportunities for learning which would inspire students on how to react to mistakes with renewed determination to understand instead of being resistant to learn [11].

Make the classroom a safe place to take the risks involved in learning by the way you treat students' attempts to learn and encourage building community of learners in your class, where everyone supports everyone else's attempt to learn. If possible, give the learners some choices in what or the way they learn [17] [18] [19].

\subsection{Inspired Students as Self Directed Learners}

Research now shows that one of the main characteristics of the inspired students is that they are mostly self-directed learners, [20]. Self-directed learning students won't be of the type of students whom depends on the teacher to make most of the learning decisions, i.e. they won't ask "What do you want in this assignment?" "How long should it be?" "Do I need to have references?" "What do I need to know for the test?" "How many homework problems should I do?".

Grow [20] and followed by Garrison [12] found that self-directed learning starts with good set of learning skills that can help teachers design learning activities and assignments that establish the foundation for self-directed learning.

Giving student learners some control of their learning processes is considered to be the first step in developing their internal locus of control. This control is found to build self-efficacy. 
Research has repeatedly shown that self-directed learning students must have confidence in their ability to succeed instead of focusing on what they can't do. Teachers need to create learning experiences that help students discover that they can do things they don't think they can [1].

Cassidy [21] showed that innovative applications of traditional classroom tools can raise the interest of the students if it is blended with new social media. Other research seen that goal-setting exercises can maintain students' commitment and enhance their intrinsic motivation keep them on track. It helped to raise the opportunities to draw on popular literature and culture while maintaining academic rigor [17] [18] [19] [22] [23] [24].

\subsection{Deepening the Learning of the Inspired Students through Critical Reflection}

Inspiring students means that teacher need to reach deeper levels of understanding where students must be able to construct meaning out of a purposeful combination of their experiences and academic materials. All too often, however, this important academic depth is sacrificed to breadth.

Critical reflection is one of the best ways to overcome this common problem. Researchers seen that teachers need to intentionally design critical reflection activities that motivate students to get engaged in deep dialogue through analyzing, reconsidering, and questioning experiences and content knowledge [14]. The students should be challenged and motivated to explain how their understanding on the subject can be enhanced through the incorporation of meaningful critical reflection activities. Through deep dialogue and interventions the students would address their misconception and even achieve more matching of their goals [25].

The reflective exercises to course-based learning outcomes and use effective strategies for engaging students in questioning prior knowledge and assumptions found to enhance the reflection to challenge simplistic conclusions and help the students to become transformative learners as confirmed by Hedberg [25]. Studies even show that consistency of experiential learning offer greater reflective opportunities for the students that they would carry throughout their [14] [20] [25].

\section{Methodology}

This research used a quantitative methodology. First a pilot study were carried by the Department of Education top management and senior teachers in the two best schools in the Kingdom of Bahrain to both illustrate the most suitable way for data collection through both interviews and questionnaires. Before the interview carried out general concept of inspiration was explained to the pilot study participants supporting the researcher. There was general guidelines to support raising a flag for those that carries symptoms and characteristics. These symptoms and characteristics can be seen from Student Learning Goal, the student passion and dream for development, the student differentiation and contribu- 
tions goals, the way the student see the Curriculum, the student school-wide relations, the personal non-educational achievements.

Two main students general codification criteria's were established in order to segregate students inspired from the competitive students and other normal students.

The Inspired Student Criteria was summarized by a moto called (Evolving Spirit) and it was made of the following five sub-criteria's:

1) Carries spirit of Aspiration, Persistence, Perseverance, Self-Actualization, Life Purposefulness, Spirit of Volunteering and Contribution;

2) Ability to meet challenges;

3) Have positive influence on others;

4) Bring in creative outcomes;

5) Have a Source of Inspiration.

The Competitive Students Criteria was summarized by a moto called (Fitness for Purpose) and it was made of the following sub-criteria's:

1) Best in Learning \& Education;

2) High Grades;

3) Best Skills;

4) High Experience in specific area;

5) Hard and Dedicated Work.

In order to measure these students' two main teams were set. The first team was focused on schools and pedagogical process and faculty, while the second team was focused on assessing the curriculum design according to the outcome of the study.

An Inspiration Pedagogical Design Team (IPDT) was established with the following purposes:

1) Explore type of the inspired students;

2) Specifiy the area or source of inspiration;

3) Create possible positive directions;

4) Learn best practices to create more inspired and high level of inspiration.

Another team called the Inspiration Curriculum Team (ICT) was established for:

1) Analysing and then Re-Engineering the curriculum towards being more inspiration;

2) Improve learning techniques and strategies;

3) Raise the Capacity of Teachers to optimize the inspiration curriculum;

4) Employment of Inspiration Sources for Development of Pedagogical Process.

\subsection{Data Collection}

A team of senior pedagogical leaders in Department of Education were selected to lead the interviews with students in two of the leading schools in Bahrain.

Both teams Inspiration Pedagogical Design Team (IPDT) and the Inspiration Curriculum Team (ICT) and after going through the pilot experience of how to interview students started a deep dialogue with the researcher to prepare train 
the trainer kit for 117 teachers that were selected from all high schools in the country to execute the inspiration assessment interviews. These interviews were supported also by surveys and the execution of the study were supervised by the 117 trained leading teacher to ensure the proper data in their relevant areas or schools thus ensure the research reliability. The pedagogical team from each school was consisting of more than 15 teachers to support the throughput of the study as efficiently as possible while it is being collected in the same time from all schools. 17,000 targeted students were invited for the interviews and the survey from all high schools from both genders.

The teams worked together to identify the top answers, that revealed by students as they were confronted with challenges that explore their level of aspiration, persistence and perseverance.

\subsection{Defining Sources of Inspiration Partners}

Part of the study was to identify the sources of inspiration that influence the inspiration of the students. Due to the complication of this process the researcher in collaboration of Educational leaders identified selected entities that would help to measure and track the inspired students or supply the study with different data. Hence, part of the research design was to define these partners based on collaboration towards both lifelong learning and inspiration based outcome and these partners were:

1) Main National University;

2) Higher Education Authority;

3) Qaulity Assurance Authority;

4) Minsitry of Labor;

5) Labor Fund;

6) Ministry of Central Information.

The identified partners agreed to give data in relevant to the defined inspired students based on students tracking by the national identity number periodically.

\subsection{Data Analysis}

Based on the students survey and interviews only $58 \%$ of students believe that they have time to discuss in class and $55 \%$ believe that they are given enough time to practice exercises.

In order to pilot the study, as discussed in the methodology, 300 students were interviewed from two of the best boys and girls schools. Out of these students 132 were selected with characteristics of persistence and perseverance towards a life main goal. The students were asked to name only one main reason they think was the reason for their inspiration. Table 1 represent the main causes seen by the students for their inspiration.

After the survey and the interviews with the students, another survey was carried for 100 selected high school teachers. $63 \%$ teachers agreed that now they are clearly trying to give more time to discover their students inspiration and about 
Table 1. Main causes seen for students inspiration.

\begin{tabular}{|c|c|}
\hline Random Causes of Inspiration Student & Number of Students \\
\hline Learning from Failure & 8 \\
\hline Influenced by Success Stories & 2 \\
\hline Life Accidents & 4 \\
\hline Volunteering & 20 \\
\hline Role Model in Family & 12 \\
\hline Peers Influences & 14 \\
\hline Community Influence & 5 \\
\hline Socialisation with People & 3 \\
\hline Welling to Sacrifice & 1 \\
\hline Love for Discovery & 2 \\
\hline Curiosity & 7 \\
\hline Love the Challenges & 9 \\
\hline Family Conditions & 12 \\
\hline School Programs & 3 \\
\hline Teachers & 2 \\
\hline School Leadership & 1 \\
\hline Economic Condition & 4 \\
\hline Social Media & 23 \\
\hline Total & 132 \\
\hline
\end{tabular}

$90 \%$ believe that now they would use all their authority to take better positive decisions.

The survey and the interviews shown that only $49 \%$ of the mentioned characteristics of the inspired could be measured. i.e. the schools didn't have the different measures to test the students inspiration. This means that $51 \%$ of the measures could not be collected by the current practices.

Total 7117 Samples of the 17,000 students were codified to either Green (Inspired Students) or Red (Non-Inspired Students). 40.11\% (2855 students) were found to be inspired and 59.89\% (4262 students) were found to be not inspired, even though they might be competitive students.

$16 \%$ of those inspired are from Scientific Cohort and 14\% of the Business \& Management Cohort, while 6\% from Industrial and 5\% from Schools of Arts and the rest from other small specialties.

$69 \%$ of the inspired students comes from parents with basic education or below a bachelor degree. Only $18.2 \%$ comes Postgraduate and Higher degrees parents. More over the results shows that $69.4 \%$ of the inspired students comes from a family of above 5 till 9 members. Actually $21 \%$ comes from large families of 10 members or more. Only $9.5 \%$ comes from small family size (less than 5 members). $56.2 \%$ of the inspired students found to come from well-established housing facilities (i.e. family owns villa), $30.6 \%$ staying in flats, and $13.2 \%$ family sharing accommodation. 
Strangely the majority of students 1033 (36\%) out of the 2855 inspired students are found to be of grades B (very good) i.e. between $80 \%-89 \%$ of grades. Only $812(28 \%)$ of these are A students. More astonishing that 1010 (35\%) students are blow $80 \%$ grades (i.e. in the grades of $\mathrm{C}$ to $\mathrm{F}$ )!

\section{Discussion and Recommendation}

This study brings in lots of areas of important issues that are rarely covered in literature and body of knowledge. The first issue is that further studies in different areas of the world with the same category i.e. high school would surely support the generalization of this important study. The second issue is that we need to think from now about the criteria for the inspired students' development through establishing: Inspired Student that: discover themselves, manage the labour market demands and help in the creation of Lifelong learning [17].

This study raise the importance of school obligation to: discover the inspired students, help the low inspired students and/or the non-inspired ones raise their inspiration. There are 3 main questions each school should look for in its students outcome. The first is that whether each of the students are unique and hard to copy. The second issue is about whether these students are a source of inspiration for their schools. The third issue is whether these students of demand by the capital market, as shown in Figure 1.

This study also raises the importance of studying the inspiration cycles that raise the observation and opportunities for each student to achieve his/her desired outcome. The research has proposed the following framework in Figure 2 to be tested or challenged by future research studies.

Students can have thoughts and moments of inspiration that come from class and extra-curricular activities as these moments are challenged with specific performance the students observation abilities would rise and also their ability to discover opportunities would be higher. This should raise the ability of the students to visualise the big picture [14].

Are each of your

Students Uniqee and hard to copy

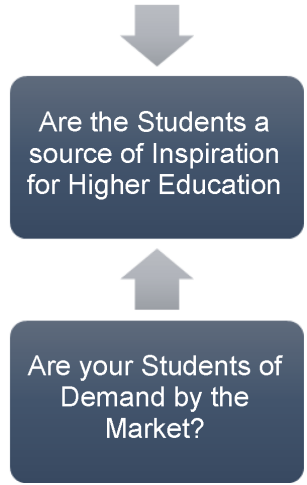

Figure 1. Illustrated the main questions that each school would look for in its students consistently. 


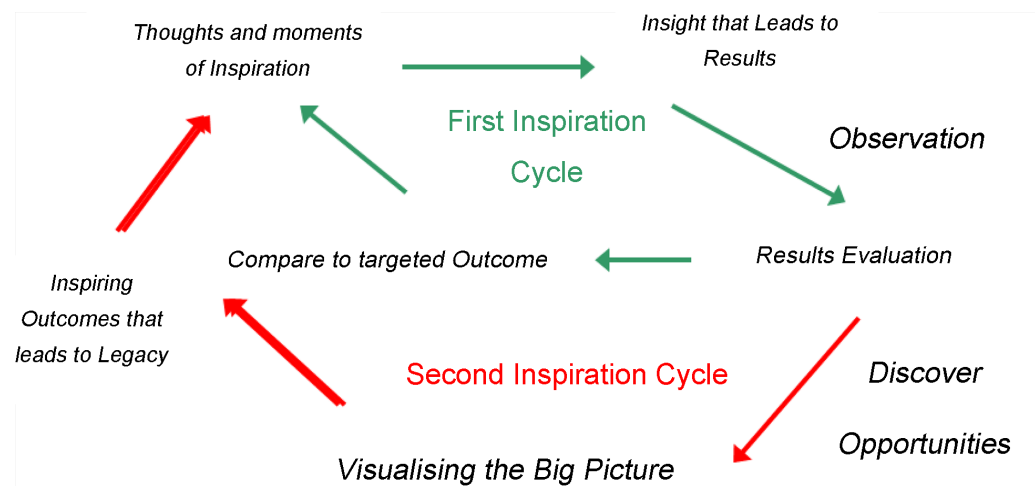

Figure 2. Proposed framework of cycles of inspiration that create inspired students with targeted outcomes that lead to legacy.

\section{Conclusions}

This research focuses on shifting the efforts of the educational leaders towards creating more inspired students that are able to influence more positive outcome in the global socio-economy development and stability. Even though the paper has limitation that it has been carried in one country and it was done over a period of two years; the way and the amount of data collected give it strong push to be generalised in other countries where the inspired students are still not identified and where the issue of high grades represents students competitiveness and future success.

The paper shows the importance of measuring both inspired students' and the conditions that created their inspiration. Schools are encouraged as per the paper results to measure the amount of inspired students and their sources of inspiration as their expected outcome. The paper also shed an alarming situation that the current measures of educational competitiveness might not cover the school inspirational efforts and sources.

The data analysis and discussion show that we can bring in more inspired students to the market starting from high school. The paper has established some criteria that can be used to both measure the inspired students' and to develop them.

Inspiration as a process, can not only empower the students to be active Learners, but also found to help them to be more engaged with high entrepreneurial spirit. Tracking students' inspiration can enhance the educational outcomes, including their academic performance. Inspiration was found also to be highly linked to student's challenges which the pedagogical team can set as part of the learning goal.

Grades as per this study are not linked with level of inspiration. Thus, inspiration can occur whatever the grades or even the economic conditions of students are. This study raises the flag that inspiration can be created and even increased amongst students, if teachers are willing and able to go beyond the course requirements.

This paper concludes with recommended learning framework that can increase the students' ability to both observe and capture opportunities. Yet, fur- 
ther studies are recommended to both test the framework and generalise the study results in both high school and beyond. It therefore highly recommended that future researches should be done to more illustrate what criteria need to be built in the future for measuring students' competitiveness for sustainable developing socio-economy. Also, it highly essential that more studies are carried in relevance to 'youth economy' and what type of methodologies needed to measure it in different contexts and settings.

\section{References}

[1] Meece, J., Blumenfeld, P. and Hoyle, R. (1988) Students' Goal Orientation and Cognitive Engagement in Classroom Activities. Journal of Educational Psychology, 80, 514-523. https://doi.org/10.1037/0022-0663.80.4.514

[2] Brophy, J. (2010) Motivating Students to Learn. 3rd Edition, Routledge, Abingdon-on-Thames.

[3] Buheji, M. and Thomas, B. (2016) Handbook of Inspiration Economy. Bookboon, London.

[4] Stubb, J., Pyhältö, K. and Lonka, K. (2011) Balancing between Inspiration and Exhaustion: PhD Students' Experienced Socio-Psychological Well-Being. Journal of Studies in Continuing Education, 33, 33-50. https://doi.org/10.1080/0158037X.2010.515572

[5] Souitaris, V., Zerbinati, S. and Al-Laham, S. (2007) Do Entrepreneurship Programs Raise Entrepreneurial Intention of Science and Engineering Students? The Effect of Learning, Inspiration and Resources. Journal of Business Venturing, 22, 566-591. https://doi.org/10.1016/j.jbusvent.2006.05.002

[6] Plucker, J. (2010) The Relationship between School Climate Conditions and Student Aspirations. The Journal of Educational Research, 91.

[7] Zakrajsek, T. (2004) Inspired Students to Set and Achieve Goals Which Really Challenged Them. University of North Carolina, Chapel Hill, The IDEA Center. http://www.ideaedu.org/Resources-Events/Teaching-Learning-Resources/Inspired-s tudents-to-set-and-achieve-goals-which-really-challenged-them

[8] Janzow, F. and Eison, J. (1990) Grades: Their Influence on Students and Faculty. New Directions for Teaching and Learning, 42, 93-102. https://doi.org/10.1002/tl.37219904210

[9] Ames, C. and Archer, J. (1988) Achievement Goals in the Classroom: Students' Learning Strategies and Motivation Processes. Journal of Educational Psychology, 80, 260-267. https://doi.org/10.1037/0022-0663.80.3.260

[10] Svinicki, M. (2004) Learning and Motivation in the Postsecondary Classroom. Anker Publishing, Bolton, MA.

[11] Feldman, K.A. (1997) Identifying Exemplary Teachers and Teaching: Evidence from Student Ratings. In: Smart, J.C. and Perry, R.P., Eds., Effective Teaching in Higher Education: Research and Practice, Agathon Press, New York.

[12] Franklin, J. and Theall, M. (1995) The Relationship of Disciplinary Differences and the Value of Class Preparation Time to Student Ratings of Teaching. New Directions for Teaching and Learning, 1995, 41-48. https://doi.org/10.1002/tl.37219956407

[13] Locke, E.A., Shaw, K.N., Sarri, L.M. and Latham, G.P. (1981) Goal Setting and Task Performance: 1969-1980. Psychological Bulletin, 90, 125-152.

https://doi.org/10.1037/0033-2909.90.1.125 
[14] Middleton, M. and Midgley, C. (1997) Avoiding the Demonstration of Lack of Ability: An Under-Explored Aspect of Goal Theory. Journal of Educational Psychology, 89, 710-718. https://doi.org/10.1037/0022-0663.89.4.710

[15] Johnson, D. and Johnson, R. (1985) Motivational Processes in Cooperative, Competitive and Individualistic Learning Situations. In: Ames, C. and Ames, R., Eds., Research on Motivation in Education, Vol. 2, Academic Press, New York, 249-286.

[16] Javeed, S. (2012) Motivation and How to Maintain It. Retrieved from University of Toronto Parents and Families eNews.

http://www.nacada.ksu.edu/Resources/Academic-Advising-Today/View-Articles/St udent-Motivation-How-to-Inspire-and-Sustain-It.aspx

[17] Boyer, S.L., Edmondson, D.R., Artis, A.B. and Fleming, D. (2014) Self-Directed Learning: A Tool for Lifelong Learning. Journal of Marketing Education, 36, 20-32. https://doi.org/10.1177/0273475313494010

[18] Angelo, T. and Cross, K. (1993) Classroom Assessment Techniques: A Handbook for College Teachers. 2nd Edition, Jossey-Bass, San Francisco, 126, 148, 197, 232.

[19] Hedberg, P. (2009) Learning through Reflective Classroom Practice: Applications to Educate the Reflective Manager. Journal of Management Education, 33, 10-36.

[20] Grow, G. (1991) Teaching Learners to Be Self-Directed. Adult Education Quarterly, 41, 125-149. https://doi.org/10.1177/0001848191041003001

[21] Caldwell, J.E. (2007) Clickers in the Large Classroom: Current Research and Best-Practice Tips. CBE-Life Sciences Education, 6, 9-20.

https://doi.org/10.1187/cbe.06-12-0205

[22] Cassidy, S. (2006) Developing Employability Skills: Peer Assessment in Higher Education. Education + Training, 48, 508-517. https://doi.org/10.1108/00400910610705890

[23] Deci, E. and Ryan, R. (1985) Intrinsic Motivation and Self-Determination in $\mathrm{Hu}$ man Behaviour. Plenum Press, New York. https://doi.org/10.1007/978-1-4899-2271-7

[24] Erwin, J.C. (2010) Inspiring the Best in Students. ASCD, Alexandria, VA.

[25] Hatton, N. and Smith, D. (1995) Reflection in Teacher Education: Towards Definition and Implementation. Teaching and Teacher Education, 11, 33-49. https://doi.org/10.1016/0742-051X(94)00012-U

\section{Submit or recommend next manuscript to SCIRP and we will provide best service for you:}

Accepting pre-submission inquiries through Email, Facebook, LinkedIn, Twitter, etc. A wide selection of journals (inclusive of 9 subjects, more than 200 journals)

Providing 24-hour high-quality service

User-friendly online submission system

Fair and swift peer-review system

Efficient typesetting and proofreading procedure

Display of the result of downloads and visits, as well as the number of cited articles

Maximum dissemination of your research work

Submit your manuscript at: http://papersubmission.scirp.org/

Or contact ajibm@scirp.org 